\title{
Experimental Results of a Single Emittance Compensation Solenoidal Magnet*
}

\author{
D. T. Palmer*, X. J. Wang ${ }^{\dagger}$, I. Ben-Zvi ${ }^{\dagger}$, R. H. Miller*, J. Skaritka
ford Linear Accelerator Center, Stanford University, Stanford, CA 94309 \\ ${ }^{*}$ Stanford Linear Accelerator Center, Stanford University, Stanford, CA 94309
†Brookhaven National Laboratory, Accelerator Test Facility, Upton, NY 11973 JUN 24997 \\ OS S I
}

Abstract

A new iron dominated single emittance compensation solenoidal magnet was designed to be integrated with the BNL/SLAC/UCLA 1.6 cell S-Band Photocathode if Gun. This emittance compensated photoinjector is now in operation at the Brookhaven Accelerator Test Facility. It has produced a $0.329 \pm 0.012 \mathrm{pC}, \tau_{95 \%}=10.9 \mathrm{psec}$ electron bunches with a normalized rms transverse emittance of $\epsilon_{n, r m s}=1.17 \pm 0.16 \pi \mathrm{mm}$ mrad. POISSON field maps were used with PARMELA to optimize the emittance compensation solenoidal magnet design. Magnetic field measurements show that at the cathode plane $B_{z} \leq 10 \mathrm{G}$ for a peak magnetic field of $B_{z, \max }=3 \mathrm{kG}$. Which is in agreement with POISSON simulation. A single emittance compensation solenoidal magnet will produces a initial angular momentum of the electron bunch that manifests itself in a initial magnetic emittance term that cannot be eliminated. This magnetic emittance $\epsilon_{\mathrm{n}, \mathrm{rms}}^{\mathrm{mag}}$ scales as $0.010 \frac{\mathrm{mm} \mathrm{mrad}}{\mathrm{G}}$ at the cathode, which is in agreement with PARMELA simulations. Experimental beam dynamics results are presented that shows relative angular rotation and spot size as a function of cathode magnetic field. These results are compared to theory.

\section{INTRODUCTION}

The BNL/SLAC/UCLA S-band emittance compensated [1] photoinjector has been installed at the Brookhaven Accelerator Test Facility(ATF) as the electron source for beam dynamics studies, laser acceleration and free electron laser experiments. The 1.6 cell if gun is powered by a single XK-5 klystron, and is equipped with a single emittance compensation solenoidal magnet. We have experimentally investigated the physical consequence of this single solenoidal magnet design as they relate to emittance growth. The simulation results, mechanical design, theory and experimental beam dynamics results of the single emittance compensation solenoidal magnet are presented.

\section{SIMULATIONS}

POISSON [2] field maps were generated for a number of different emittance compensation magnet designs. PARMELA [3] was then used to evaluate these designs as a function of the minimum emittance attainable using the ATF beamline as a model. These field maps

- Work supported by the Department of Energy, contracts DE-AC0376 SF00515 and DE-AC02-76CH00016 were developed using a Dirichlet boundary condition at the cathode plane. Due to mechanical constraints of the BNL/SLAC/UCLA 1.6 cell S-band rf gun [4], the compensation magnet could not be positioned in the optimal emittance compensation position but at the location shown in figure 1 which gives a $15 \%$ higher emittance than the optimum.

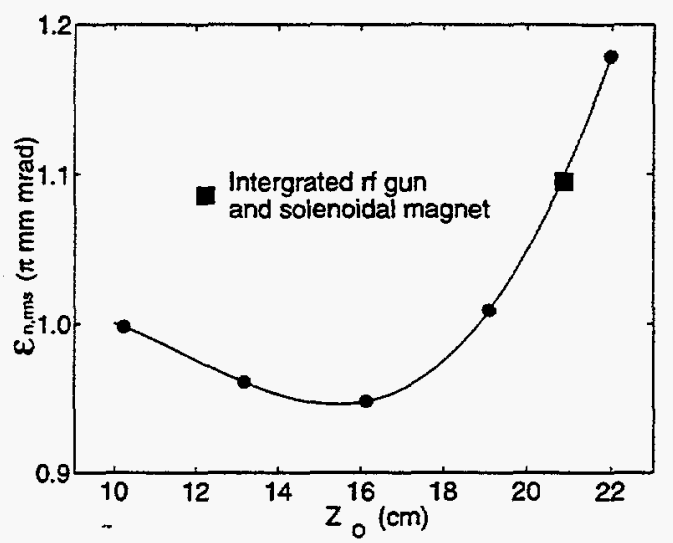

Figure 1: PARMELA simulations of the normalized rms emittance versus emittance compensation magnet position

\section{SOLENODAL MAGNET DESIGN}

The solenoidal magnet is constructed out of eight double layer hollow core copper conductor pancakes. The flux return was manufactured out of 1006 steel, as are the seven dipole field flux aligners [5]. These dipole field flux aligner are used to eliminate any dipole fields that arise from the current pancake asymmetries and misalignments during assembly. Penetrations thru the flux return were designed to have four fold symmetry. The external current conductors are fed to alternate sides of the solenoid to eliminate a dipole contribution due to the individual pancake conductor crossovers. A schematic drawing of the solenoidal magnet is show in figure 2.

In the previous ATF emittance compensation magnet design the solenoidal magnet was an air core magnet. We have extended this initial design that included dipole field straighteners to incorporate an iron flux return that eliminates the need of a congruent magnet symmetrically located upstream of the cathode to buck the cathode magnetic field to zero. The use of the magnetic flux return has decreased the cathode magnetic field to $B_{z} \leq 10 \mathrm{G}$ for a peak magnetic field of $B_{z, \max }=3 \mathrm{kG}$ as seen in figure 3 . 


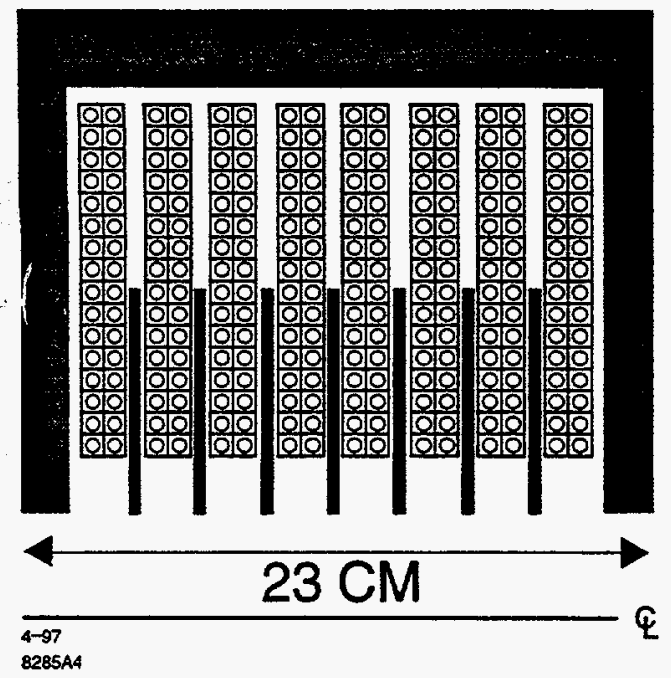

Figure 2: Compensation Magnet Design

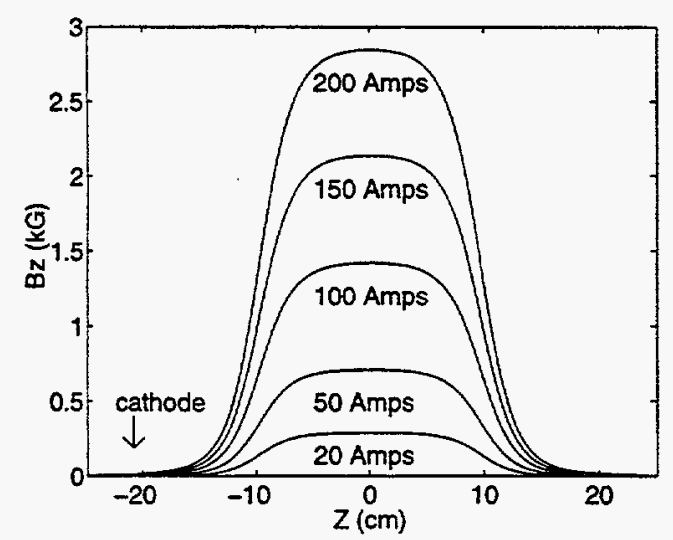

Figure 3: Magnetic Field Measurements

A bucking magnet is located at the upstream end of the gun. It is only used for beam dynamics studies. $A \cos (\theta)$ deflection magnet is located in the emittance compensation magnet bore. This deflection magnet is used for energy measurements of the electron bunch energy at the exit of the gun.

\section{THEORY}

In this section we will delineate the effect of the finite cathode magnetic field due to the bucking magnet. There are three effects that will studied first the relative angular rotation due to the cathode magnetic field, spot size and finally the normalized rms emittance due to this magnetic field. From Busch's theorem [6] we know that

$$
\dot{\theta}=\frac{\mathrm{e}}{2 \gamma \mathrm{m}_{\mathrm{o}}}\left(\mathrm{B}_{\mathrm{z}_{\mathrm{o}}}-\mathrm{B}_{\mathrm{z}}\right)
$$

where $B_{z_{o}}$ and $r_{o}$ is the cathode magnetic field and laser spot size. Integrating equation 1 we find that the angular rotation as a function of cathode magnetic field varies linearly with the cathode magnetic field.

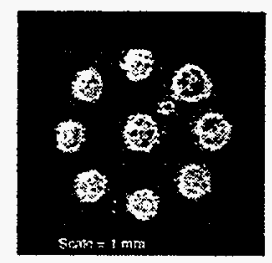

Figure 4: 8 fold symmetric beamlets

$$
\delta \theta=\int \frac{\mathrm{e}}{2 \beta \gamma \mathrm{m}_{\mathrm{o}} \mathrm{c}} \mathrm{dz} \mathrm{B}_{\mathrm{z}_{\mathrm{o}}}
$$

Busch's theorem can also be used to study the effect of cathode magnetic field on spot size. Starting with the definition of $x_{\text {rms }}^{\prime}$.

$$
\mathrm{x}_{\mathrm{rms}}^{\prime}=\frac{\mathrm{p}_{\mathrm{x}, \mathrm{rms}}}{\mathrm{p}_{\mathrm{z}}}=\frac{\mathrm{v}_{\mathrm{x}, \mathrm{rms}}}{\beta \mathrm{c}}=\frac{\mathrm{er}_{\mathrm{o}}\left|\mathrm{B}_{z_{\mathrm{o}}}\right|}{4 \beta \gamma \mathrm{m}_{\mathrm{o}} \mathrm{c}}
$$

Which follows from the definition of rms velocities we know that

$$
\mathrm{v}_{\mathrm{x}, \mathrm{rms}}=\sqrt{\frac{\iint \mathrm{r}^{2} \dot{\theta}^{2} \cos ^{2}(\theta) \mathrm{rdrd} \theta}{\iint \mathrm{rdrd} \theta}}
$$

Therefore, the rms spot size increases as $\left|B_{z_{0}}\right|$

$$
\mathrm{x}_{\mathrm{rms}}=\int \mathrm{x}_{\mathrm{rms}}^{\prime} \mathrm{dz}=\int \frac{e \mathrm{r}_{\mathrm{o}}}{4 \beta \gamma \mathrm{m}_{\mathrm{o}} \mathrm{c}} \mathrm{dz}\left|\mathrm{B}_{\mathrm{z}_{\mathrm{o}}}\right|
$$

The magnetic emittance scales as $\epsilon_{\mathrm{n}, \mathrm{rms}} \propto \mathrm{r}_{\mathrm{o}}^{2}\left|\mathrm{~B}_{\mathrm{z}_{\mathrm{o}}}\right|$ given in equation 6 where we assume that the $\left\langle\mathrm{xx}^{\prime}\right\rangle=0$.

$$
\epsilon_{\mathrm{n}, \mathrm{rms}}=\beta \gamma \sqrt{\left.<\mathrm{x}^{\prime 2}><\mathrm{x}^{2}\right\rangle}=\frac{\mathrm{er}_{\mathrm{o}}^{2}\left|\mathrm{~B}_{z_{\mathrm{o}}}\right|}{8 \mathrm{~m}_{\mathrm{o}} \mathrm{c}}
$$

\section{EXPERIMENTAL RESULTS}

Due to the small but finite field at the if gun cathode the electron bunch are produced with a finite angular momentum. We have measured the relative angular rotation due to this finite field. In this experiment a 8-fold symmetric mask [7] [8] was inserted into the the laser beam thereby producing the laser profile on the cathode shown in figure 4 .

The smallest beamlet located at $45^{\circ}$ is used to break the symmetry. In this way we were able to measure the betatron rotation of the beam thru the solenoidal magnet which was found to be approximately $90^{\circ}$. The 8 -fold beamlet relative angular rotation was measured as a function of bucking magnet field for point to point imaging of the 8-fold beamlets from the cathode to a beam profile monitor located $66.4 \mathrm{~cm}$ from the cathode. Figure 5 represents the relative angular rotation of the 8-fold symmetric beamlets due to the cathode magnetic field and has a linear dependence predicated in equation 2.

The rms spot size as a function of cathode magnet field was measured at both low and high energy. The functional dependence of the high energy spot size data in figure 7 


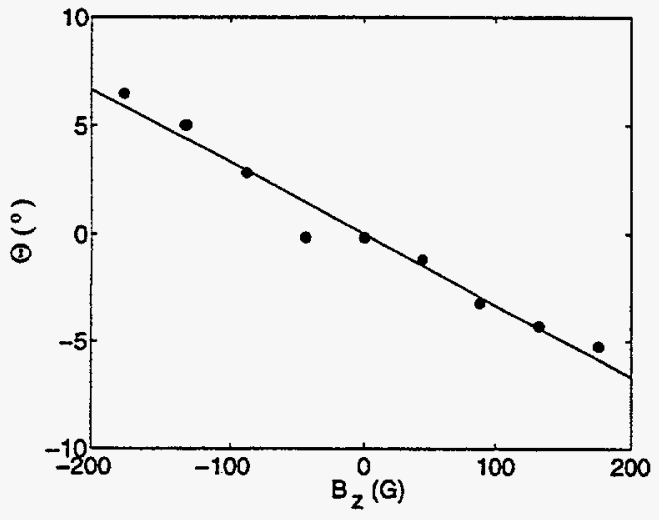

Figure 5: $\Phi_{\text {rel }}(z=0)$ versus $B_{z}(z=0)$

\begin{tabular}{|l|l|}
\hline Experimental Result & $0.010 \frac{\pi \mathrm{mm}-\mathrm{mrad}}{\mathrm{G}}$ \\
\hline PARMELA & $0.006 \frac{\pi \mathrm{mm}-\mathrm{mrad}}{\mathrm{G}}$ \\
\hline THEORY & $0.007 \frac{\pi \mathrm{mm}-\mathrm{mrad}}{\mathrm{G}}$ \\
\hline
\end{tabular}

Table 1: Comparison of experimental results, simulation and theory for the emittance growth due to the cathode magnetic field

has been fit to equation 5 with a minimum spot size occurring with a cathode magnetic field of $-5 \mathrm{G}$. The cathode field with the bucking magnet off is $+4 \mathrm{G}$. The low energy spot size data in figure 6 is not fitted to equation 5 since the beam is space charge dominated in the low energy regime. Fitting this data with two linear functions has the minimum spot size occurring at the $-3.6 \mathrm{G}$. Which is consistent with the high energy minimum spot size bucking field. This data indicates that the cathode field can not be zeroed better than the mechanical construction and alignment of the photoinjector itself.

Due to experimental instabilities it was not possible to measure the emittance growth due to the induced cathode magnetic field. From the spot size variation at high energy due to the induced cathode magnetic field and the correlation between spot size and measured $\epsilon_{\mathrm{n}, \mathrm{rms}}$ [9], the emittance growth as a function of cathode magnetic field can be estimated. In table 1 the correlated experimental results of $\epsilon_{\mathrm{n}, \mathrm{rms}}$ growth as a function of induced cathode magnetic field is presented along with PARMELA simulation and theoretical [10] predications.

\section{CONCLUSION}

We have present the design and experimental results of a single emittance solenoidal magnet. Relative angular rotation, low and high energy rms spot size have been presented as a function of cathode magnet field. Mechanical constraints limit the compensation magnet to a position that is not optimal for the emittance compensation process. Redesigning the waveguide feed into the full cell would correct this limitation in the injector design.

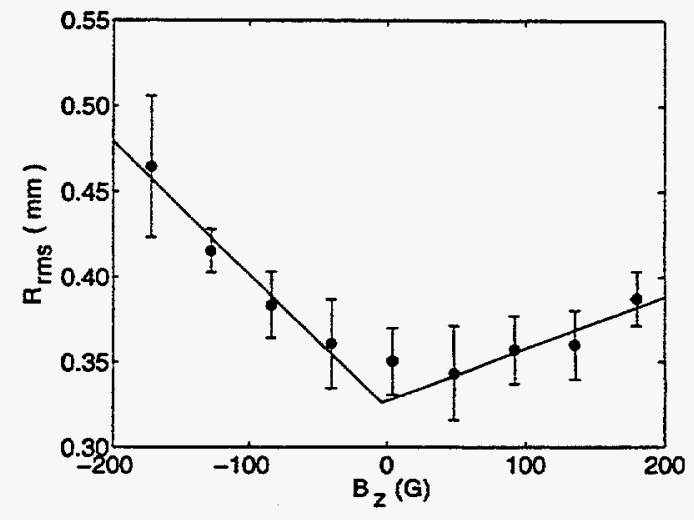

Figure 6: Low energy $R_{r m s}$ versus $B_{z}(z=0)$

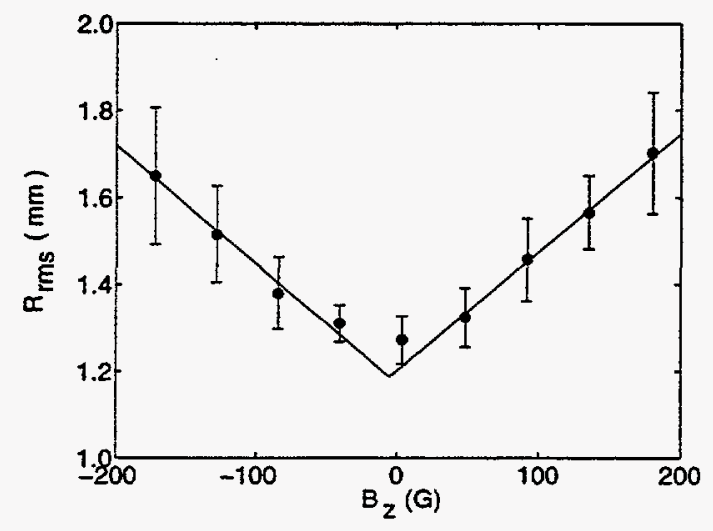

Figure 7: High energy $R_{r m s}$ versus $B_{z}(z=0)$

\section{ACKNOWLEDGMENT}

The authors would like to thank the technical staff at UCLA, SLAC and BNL for all their dedicated work on this project. We would also like to thank Dr. K. Halbach for his technical assistance in the design of the single emittance compensation solenoidal magnet and Dr. V. Yakimenko for conducting the magnetic field measurements on the solenoidal magnet.

\section{REFERENCES}

[1] B. E. Caristen, NIM, A285, 313 (1989)

[2] K. Halbach and R. F. Holsinger, Particle Accelerators, 7, 213 (1976)

[3] L. M. Young, private communications

[4] D. T. Palmer et al., Proc. 1995 Part. Accel. Conf. (1995) p. 982

[5] K. Halbach, LBL 4270

[6] H. Busch, Z. Phys., 81, 974 (1926)

[7] Z. Li, Ph.D. Thesis

[8] D. W. Feldman et al., IEEE J. Quantum Electronic, 27, 12, 2636-2643 (1991)

[9] D. T. Palmer et al., Proc. 1997 Part. Accel. Conf., 2C.10

[10] K. Flotmann, private communications 


\section{DISCLAIMER}

This report was prepared as an account of work sponsored by an agency of the United States Government. Neither the United States Government nor any agency thereof, nor any of their employees, makes any warranty, express or implied, or assumes any legal liability or responsibility for the accuracy, completeness, or usefulness of any information, apparatus, product, or process disclosed, or represents that its use would not infringe privately owned rights. Reference herein to any specific commercial product, process, or service by trade name, trademark, manufacturer, or otherwise does not necessarily constitute or imply its endorsement, recommendation, or favoring by the United States Government or any agency thereof. The views and opinions of authors expressed herein do not necessarily state or reflect those of the United States Government or any agency thereof. 


\section{DISCLAMIER}

Portions of this document may be illegible in electronic image products. Images are produced from the best available original document. 